\title{
Seed bank persistence of clonal weeds in contrasting habitats: implications for control
}

\author{
Elze Hesse $\cdot$ Mark Rees $\cdot$ Heinz Müller-Schärer
}

Received: 12 January 2006/ Accepted: 4 August 2006/Published online: 5 September 2006

(C) Springer Science+Business Media B.V. 2006

\begin{abstract}
The ability of weeds to form a seed bank is important for their population dynamics and management because it provides a refuge enabling reinvasion after established target plants have died. However, knowledge of the differential seed behaviour of individual species over multiple years and varying environmental conditions is surprisingly rare but necessary for effective control of diverse weed populations. We established a seed burial experiment in alpine habitats differing in management regime (i.e., forest, hay meadow and pasture) to determine whether seeds of the unpalatable perennial weeds, Veratrum album (white hellebore) and Gentiana lutea (yellow gentian) were able to delay germination and remain viable over 3 years. Our study shows that both species formed a short-term persistent seed bank; in the third-year, the soil seed banks of both species were
\end{abstract}

E. Hesse $(\bowtie) \cdot$ H. Müller-Schärer

Unit of Ecology \& Evolution, Department of Biology, University of Fribourg, Chemin du Musée 10,

CH-1700 Fribourg, Switzerland

e-mail: elze.hesse@plants.ox.ac.uk

Present Address:

E. Hesse

Department of Plant Sciences, University of Oxford, South Parks Road, Oxford OX1 3RB, UK

M. Rees

Department of Animal \& Plant Sciences, University of Sheffield, Western Bank, S10 2TN Sheffield, UK nearly depleted, having declined to $<5 \%$ of their original size. Both species had strikingly different germination strategies: G. lutea seeds mainly germinated in their first-year, whilst the majority of $V$. album seeds germinated in their second-year. The fraction of dormant G. lutea seeds increased with seed age, indicating that seeds remained viable after forgoing germination in the previous year. Habitat-specific differences in seed germination increased with seed age, with germination fractions being lowest in moist hay meadows. This suggests that the negative effects of anoxic conditions became more pronounced as seeds aged in hay meadows. Conversely, seed dormancy was equal among habitats. The absence of a long-term persistent seed bank has important implications for the management of both nuisance and endangered-plant populations. In the case of $V$. album and G. lutea, re-colonization of habitats from the seed bank is unlikely after established plants have been removed.

Keywords Alteration grassland management · Artificial seed burial · Gentiana · Infestations · Short-term persistent seed bank $\cdot$ Veratrum

\section{Introduction}

Alpine grasslands are species-rich and have a long history of grazing by livestock. In Europe, there 
has been a dramatic shift in alpine grassland management towards more extensive grazing and even complete abandonment of management, especially in agriculturally marginal areas (e.g. MacDonald et al. 2000; Kleijn and Müller-Schärer 2006). In general, extensive grazing may lead to the competitive dominance of a few unpalatable plant species with consequent decreases in local plant species-richness (Augustine and McNaughton 1998). Traditionally, these unpalatable plants were removed manually but due to increasing labour costs this management strategy has often been discontinued, leading to higher local weed densities and abandonment of infested fields (Ammon and Müller-Schärer 1999). Hence, unpalatable plants may threaten the biodiversity of alpine grasslands, ultimately leading to species impoverishment of these systems.

Most of the unpalatable alpine plant species are perennial herbs that rely on both seeds and vegetative reproduction for population persistence and growth (e.g., Gentiana lutea, Rumex alpinus, Veratrum album). Seeds provide an essential link in the population dynamics of these species allowing the establishment of individuals and founding of new populations via dispersal both in space and time (Rees 1996). The timing of seed germination is also a critical determinant of reproductive success (Donohue et al. 2005a) and is often controlled by seed dormancy (i.e., seeds that do not germinate in spite of being placed into conditions generally suitable for germination), which can be lost or acquired in response to environmental stimuli such as temperature (Allen and Meyer 1998; Cavieres and Arroyo 2001; Adondakis and Venable 2004), soil moisture (Murdoch and Ellis 1992; Galatowitsch and van der Valk 1996; Bekker et al. 1998c) and nutrient concentration (Bekker et al. 1998b). Seed dormancy is thought to have evolved in response to unpredictable environmental variability and might lead to the existence of soil seed banks-populations of viable seeds in the soil (e.g. Ellner 1985; Evans and Cabin 1995; Thompson et al. 1997; Easterling and Ellner 2000; Rice and Dyer 2001).

Soil seed banks play an important role in many plant populations as they can buffer populations from temporal variation (Klinkhamer et al. 1987), mitigate the demographic effects of reproductive failure (Evans and Cabin 1995) and conserve genetic variation (Menges 2000). An understanding of seed behaviour in the soil is thus essential for the management of plant populations. Seed bank dynamics have therefore been studied and modelled extensively to predict emergence and population development, especially for weeds (e.g., Buckley et al. 2004). As most plant species have a wide distribution range encompassing a variety of ecological habitats, seed dormancy strategies must be appropriate for a wide range of environmental conditions. Surprisingly, few studies have actually addressed soil seed bank persistence of weed species in a range of habitats over multiple years.

The toxic long-lived, clonal weeds $V$. album L. (Liliales, Melanthiaceae) and G. lutea L. (Gentianaceae) typically occur in a wide range of alpine habitats throughout Eurasia (Kleijn et al. 2005), where they can form dense problematic infestations. As alpine habitats are characterized by long, cold winters, short growing seasons and the irregular, recurrent occurrence of calamities (e.g., late spring frost), delayed germination may be an adaptive bet-hedging strategy (e.g., Venable and Brown 1988). Numerous studies have reported the presence of soil seed banks in arctic and alpine habitats (Arroyo et al. 1999; Funes et al. 2003). However, due to the harsh climate in these environments vegetative reproduction may be even more advantageous than sexual reproduction, as vegetative reproduction provides for population maintenance in times and places less favourable for seed production and seedling establishment (Bierzychudek 1985). Indeed, the ability to reproduce vegetatively in addition to reproduction by seeds is known to be an important feature of alpine plant life (e.g., Körner 1999). Life history theory predicts that life history attributes that reduce the impact of environmental variation on fitness such as seed dormancy, adult longevity and vegetative or clonal reproduction, will show patterns of negative co-variation (Rees 1994). According to this pattern, increased adult longevity and adult vegetative spread should select against seed dormancy. Theory thus predicts seed dormancy to be limited in long-lived clonal species, such as $V$. album and $G$. lutea. 
Alternatively, if seed dormancy appears to be considerable, it may provide populations with a refuge in time, enabling them to reinvade sites long after parent plants have died. In this case, population management strategies should be developed, which include both measures to reduce the magnitude of established problematic infestations as well as the number of seeds present in the soil seed bank.

To enable population management strategies of unpalatable weed species to be effectively targeted and to understand the ecological factors governing seed longevity, we determined whether $V$. album and $G$. lutea were able to delay seed germination and form a persistent soil seed bank. Soil seed banks can be classified as (1) transient when seeds persist in the soil for less than 1 year; (2) short-term persistent when seeds persist in the soil for at least 1 year but less than 5 years; and (3) long-term persistent when seeds persist in the soil for at least 5 years (Thompson et al. 1997). As the percentage of seeds in the seed bank that generate seedlings might vary among species and environmental conditions (e.g., Thompson and Grime 1979; Buhler and Hartzler 2001), we investigated (1) whether $V$. album and $G$. lutea have different germination strategies; and (2) whether seed bank depletion, seed germination and dormancy differ between soils of environmentally contrasting habitats. In order to answer these questions we created experimental soil seed banks in three main habitats from the species' distribution range (i.e., forest, hay mea- dow and pasture) covering a wide range of abiotic and biotic conditions. As environmental conditions are known to vary considerably we assessed seed bank depletion rates in several regions over 3 years and focused on the environmental plasticity of seed germination and dormancy responses of unpalatable weeds. Finally, we discuss the implications of our findings for the successful management of unpalatable weed populations and hence the maintenance of species-rich alpine grasslands.

\section{Methods}

Study species

The long-lived perennials $V$. album L. and G. lutea L. contain high levels of toxic substances rendering them unpalatable to cattle. Both species can be found throughout Eurasia in a wide range of (sub)-alpine habitats, where $V$. album typically grows in relatively moist areas, whilst $G$. lutea can be found in drier areas; they mainly co-occur in pastures (Table 1). Although $V$. album and $G$. lutea appear to have comparable life histories, the ecology of G. lutea is not described in great detail. $V$. album individuals flower infrequently, once every 4-8 years; seed production is thus highly variable between populations and years. On average, $V$. album individuals produce considerably less seeds compared to G. lutea individuals (Table 1). Vegetative

Table 1 Description of the biology of Veratrum album and Gentiana lutea. Values denote the mean trait value \pm SE

\begin{tabular}{|c|c|c|}
\hline Species & Veratrum album & Gentiana lutea \\
\hline Distribution & $\begin{array}{l}\text { Eurasia; in central } \\
\text { Europe }>800 \mathrm{~m} \text { a.s.l. }{ }^{\mathrm{a}}\end{array}$ & $\begin{array}{l}\text { Pyrenees to Asia minor; } \\
\text { in central Europe }>700 \mathrm{~m} \text { a.s.l. }{ }^{\mathrm{b}}\end{array}$ \\
\hline Typical habitat & $\begin{array}{l}\text { Moist grasslands } \\
\text { and open forests }\end{array}$ & $\begin{array}{l}\text { Dry calcareous pastures } \\
\text { grazed by cattle }\end{array}$ \\
\hline Breeding system & Self-incompatible ${ }^{\mathrm{d}}$ & Self-incompatible ${ }^{\mathrm{b}}$ \\
\hline $\begin{array}{l}\text { Mean (range) seed } \\
\text { production plant }^{-1}\end{array}$ & ca. $700(20-2000)^{\mathrm{e}}$ & ca. $6000(0-12400)^{\mathrm{b}}$ \\
\hline Seed mass $(\mathrm{mg})^{\mathrm{f}}$ & $3.21 \pm 0.01$ & $1.09 \pm 0.02$ \\
\hline Seed length $(\mathrm{mm})^{\mathrm{g}}$ & $9.90 \pm 0.11$ & $3.81 \pm 0.04$ \\
\hline Seed width $(\mathrm{mm})^{\mathrm{g}}$ & $3.74 \pm 0.07$ & $2.62 \pm 0.04$ \\
\hline
\end{tabular}

Notes: ${ }^{a}$ Schaffner et al. (2001), ${ }^{\mathrm{b}}$ Kery et al. (2000), ${ }^{\mathrm{c}}$ Kleijn et al. (2005), ${ }^{\mathrm{d}}$ Kleijn and Steinger (2002), ${ }^{\mathrm{e}}$ mean seed production obtained from 58 randomly assigned $V$. album inflorescences, ${ }^{\mathrm{f}}$ calculated using 10 replicates of 50 seeds per species from the bulk seed sample, ${ }^{\mathrm{g}}$ calculated using 100 seeds per species from the bulk seed sample 
reproduction in $V$. album occurs after flowering as the apical meristem dies and is replaced by one or more lateral buds; hence sexual and vegetative reproduction are linked. Seeds of both species possess small wing-like structures; G. lutea seeds are relatively small compared to $V$. album seeds (Table 1). Seeds are retained in dehiscent capsules until they are dispersed in late autumn, winter or spring. Estimates of natural seed bank densities are not available for both species.

Seed collection and burial

Seeds were collected in autumn 2002 when the capsules were ripe. As plants flower infrequently we collected $V$. album seeds from a single pasture population (Gran San Bernardo, Italy; $45^{\circ} 51.27^{\prime} \mathrm{N}, 7^{\circ} 08.36^{\prime} \mathrm{E}$; $2600 \mathrm{~m}$ a.s.l.), whilst $G$. lutea seeds originated from several pasture populations due to limited seed numbers within a single population (collected near seed burial sites, Table 2). For both species, seeds originating from over 80 different individuals were combined into a single-species bulk seed sample. Within 30 days after seed collection, 50 air-dried seeds per species were mixed with $25 \mathrm{~cm}^{3}$ of sterilized soil (Dystric Cambisol, collected at Spittel Gantrisch; $46^{\circ} 40.19^{\prime} \mathrm{N}, 7^{\circ} 21.37^{\prime} \mathrm{E}$; $1280 \mathrm{~m}$ a.s.l.) and enclosed in nylon mesh bags. The seed-sand mixture thus gave a seed density of 2000 seeds $\mathrm{dm}^{-3}$ soil. The mesh size $\left(1 \mathrm{~mm}^{2}\right)$ of the seed bags was small enough for seeds not to get lost through water percolation and/or soil perturbation by soil organisms but large enough for the smaller fraction of the soil fauna to enter; hence, seeds were exposed to conditions similar to the natural environment.

We created artificial soil seed banks in five regions in the Swiss Pre-Alps and one region in the Swiss Jura (Table 2). Within each region, seed banks were established in three contrasting habitats i.e. Picea abies dominated forests, hay meadows and extensively grazed pastures; these habitats represent the major vegetation and management types of the species' distribution range. The species compositions of these pastures and hay meadows are very similar as $90 \%$ of the species occur in both habitats (Schlapfer et al. 1998), suggesting that the abiotic conditions are not dissimilar (Kleijn and Steinger 2002). In the Pre-Alps, the most common herbaceous species were Festuca rubra, Agrostis capillaris, Polygonum bistorta, $V$. album and G. lutea (Kleijn and Müller-Schärer 2006). In the Jura Mountains, the vegetation was dominated by $F$. rubra, A. capillaris, Cynosurus cristatus, Alchemilla xantochlora

Table 2 Locality names, altitudes and geographical coordinates of the 18 study sites located in the Swiss Pre-Alps (1, 3-6) and Swiss Jura Mountains (2)

\begin{tabular}{lllll}
\hline Region & Habitat & Altitude & Latitude & \\
& & Longitude \\
\hline (1) Spittel Gantrisch & Forest & 1321 & $46^{\circ} 40.18^{\prime} \mathrm{N}$ & $7^{\circ} 21.37^{\prime} \mathrm{E}$ \\
& Hay meadow & 1190 & $46^{\circ} 40.72^{\prime} \mathrm{N}$ & $7^{\circ} 21.15^{\prime} \mathrm{E}$ \\
& Pasture & 1280 & $46^{\circ} 40.19^{\prime} \mathrm{N}$ & $7^{\circ} 21.37^{\prime} \mathrm{E}$ \\
(2) Col de Marchairuz & Forest & 1430 & $46^{\circ} 32.60^{\prime} \mathrm{N}$ & $6^{\circ} 14.23^{\prime} \mathrm{E}$ \\
& Hay meadow & 1020 & $46^{\circ} 35.97^{\prime} \mathrm{N}$ & $6^{\circ} 13.63^{\prime} \mathrm{E}$ \\
& Pasture & 1310 & $46^{\circ} 32.24^{\prime} \mathrm{N}$ & $6^{\circ} 13.37^{\prime} \mathrm{E}$ \\
(3) Teysachaux & Forest & 1200 & $46^{\circ} 30.62^{\prime} \mathrm{N}$ & $6^{\circ} 56.09^{\prime} \mathrm{E}$ \\
& Hay meadow & 1170 & $46^{\circ} 31.51^{\prime} \mathrm{N}$ & $6^{\circ} 59.14^{\prime} \mathrm{E}$ \\
(4) Dent de Lys & Pasture & 1285 & $46^{\circ} 32.08^{\prime} \mathrm{N}$ & $6^{\circ} 58.99^{\prime} \mathrm{E}$ \\
& Forest & 1425 & $46^{\circ} 31.53^{\prime} \mathrm{N}$ & $6^{\circ} 59.28^{\prime} \mathrm{E}$ \\
& Hay meadow & 1180 & $\mathrm{~N}$ & $6^{\circ} 58.17^{\prime} \mathrm{E}$ \\
(5) La Braye & Pasture & 1470 & $46^{\circ} 27.03^{\prime} \mathrm{N}$ & $6^{\circ} 59.14^{\prime} \mathrm{N}$ \\
& Forest & 1555 & $46^{\circ} 27.44^{\prime} \mathrm{N}$ & $7^{\circ} 08.01^{\prime} \mathrm{E}$ \\
& Hay meadow & 1330 & $46^{\circ} 27.01^{\prime} \mathrm{N}$ & $7^{\circ} 09.39^{\prime} \mathrm{E}$ \\
(6) Col des Mosses & Pasture & 1545 & $46^{\circ} 25.56^{\prime} \mathrm{N}$ & $7^{\circ} 07.91^{\prime} \mathrm{E}$ \\
& Forest & 1405 & $46^{\circ} 25.49^{\prime} \mathrm{N}$ & $7^{\circ} 06.47^{\prime} \mathrm{E}$ \\
& Hay meadow & 1360 & $7^{\circ} 06.79^{\prime} \mathrm{E}$ \\
& Pasture & 1525 & $7^{\circ} 09.39^{\prime} \mathrm{E}$ \\
\hline
\end{tabular}


aggr., Prunella vulgaris, V. album, G. lutea and Ranunculus tuberosus (Kleijn and Müller-Schärer 2006; Vandenberghe et al. 2006). In general, hay meadows tended to be moister than the forests and pastures, which occurred on slightly steeper slopes and higher altitudes (Table 2); the altitudes of the sites ranged 1020-1555 m a.s.l. Hay meadows are mown yearly after 15 July, before the majority of $V$. album and G. lutea individuals are able to set seed and disperse. In general, pastures are grazed from the beginning of June until the end of August, coinciding with the growing season of the two study species. Each of the 18 seed banks consisted of 15 seed bags per species, which were buried at random within a 1$\mathrm{m}^{2}$ plot in autumn 2002 by lifting the soil with a soil core (10-cm diameter) and inserting a bag at ca. 5-cm depth. Retrieval bags were buried at 5 -cm depth to reduce the risk of cattle and/or avalanches destroying the seed burial sites.

\section{Pre-burial germination test}

We examined whether seeds were able to germinate without any stratification by carrying out a germination test on 10 replicates of 50 airdried seeds per species at the time of artificial seed burial. Germination of these seeds was assessed by transferring them to moistened filter paper in Petri dishes placed in a growth cabinet providing 12 -h light at $20^{\circ} \mathrm{C}$ and 12 -h darkness at $5^{\circ} \mathrm{C}$. The germination status was monitored every 2-3 days. After 30 days the germination test was terminated and the seeds that did not germinate were tested for viability by crushing them beneath the flat side of a pair of forceps (Sawma and Mohler 2002). Hard and light-coloured seeds were considered viable whilst soft and browncoloured seeds were regarded as dead. To confirm that these seeds were viable, we performed a tetrazolium viability test (Cottrell 1947) by cutting the seeds laterally and placing them in a $1 \%$ tetrazolium solution for ca. $6 \mathrm{~h}$. Red colouration of the embryo indicated the presence of respiring tissue, and thus a viable seed. As virtually all of the seeds physically judged to be viable also stained red, we assessed the viability of seeds in subsequent years by crushing them beneath a pair of forceps.
Seed exhumation

The fate of seeds was monitored for 3 years by exhuming five replicate seed bags per species directly after snow melt in spring 2003-2005 at the onset of natural seed germination, leading to a maximum number of 250 seeds per year per species per site at $100 \%$ retrieval efficacy. The outside of the seed bags was washed and cleaned of any soil or seeds. The content of the seed bags was washed onto a 5-mm sieve, which was placed over a $0.5-\mathrm{mm}$ sieve, thereby removing both coarse and fine soil material, roots and vegetative parts (Ter Heerdt et al. 1996). The mesh size was small enough to recover $G$. lutea seeds. The number of remaining seeds within each bag was counted and germination, viability and mortality of the retrieved seeds was tested as described above. The difference between the 50 seeds in each bag and the number of seeds retrieved at each exhumation represents the seeds lost due to processes as deterioration, early germination and predation.

\section{Data analysis}

The yearly available seed pool per species was divided into the proportion of seeds that germinated (germination), the proportion that did not germinate but still had a hard seed coat (viable) and the remaining proportion was considered non-viable (dead). To avoid pseudo-replication, we used the total number of seeds per species from the replicate seed bags ( $n=5$ at $100 \%$ retrieval efficacy) to calculate the proportion of seeds in each seed category. In the first-year, the proportion of seeds in the different seed categories was calculated by dividing the total number of seeds in each category by the total number of seeds sown per sampling plot. For subsequent years, the proportion of seeds in the different seed categories was calculated by dividing the total number of seeds in each category by the total number of seeds retrieved per sampling plot at each exhumation in spring.

As the experimental $V$. album soil seed bank was nearly depleted in the third-year, we only analyzed the data of the first 2 years of the seed burial experiment. The effect of seed age, habitat 
and species on the proportion of seeds in each category was analyzed using linear mixed-effects (LME) models (Pinheiro and Bates 2000) with site (random), seed age, habitat (nested in site) and species as explanatory variables. LME models were used as data tended to become more unbalanced over time (i.e., not all seed bags could be retrieved) and they enabled us to model correlations that often exist within grouped data. To achieve normality of standardized residuals, seed germination (arcsine square root), viability (fourth square root) and mortality (arcsine square root) data were transformed. In addition to these transformations, we extended the LME models to include a variance function, correcting for heteroscedastic within-group errors (Pinheiro and Bates 2000). The minimal adequate model was arrived at by deletion of explanatory variables one at the time from the full model. The depleted model was then compared with the full model using an $F$-test of the likelihood ratios and maximum likelihood estimates (Pinheiro and Bates 2000). Restricted maximum likelihood, being less biased, was used for parameter estimation of the most parsimonious model. Significance tests were based on marginal Sum of Squares (Type III). All analyses were performed with the $R$ statistical programme ( $R$ version 2.1).

\section{Results}

Germination and viability of seeds before burial

For both V. album and G. lutea, only $0.4 \%$ of the seeds germinated, suggesting a need for stratification or after-ripening to break seed dormancy. At the end of the 30-day germination period on the moist filter paper the majority of the remaining seeds were still viable (mean $\pm \mathrm{SE}$ for V. album: $92.6 \pm 0.6 \%$; G. lutea: $78.8 \pm 0.9 \%)$.

\section{Seed retrieval}

One year after seed burial, all seed bags could be recovered $(N=180)$. Irrespective of habitat, $95.7 \pm 0.5 \%($ mean $\pm \mathrm{SE})$ of the $V$. album seeds and $94.4 \pm 0.4 \%$ of the $G$. lutea seeds could be retrieved in the first-year, indicating that a low percentage of seeds was either lost due to the detrimental effects of fungi, insect predation and/or pre-mature seed germination in the soil during winter (Fig. 1). Not all seed bags could be successfully recovered in subsequent years ( $V$. album: 89\%; G. lutea: 88\% in 2004, V. album: 73\%; G. lutea: $72 \%$ in 2005). Seed bank depletion seemed to be high as only $60.4 \pm 3.0 \%$ of the $V$. album seeds

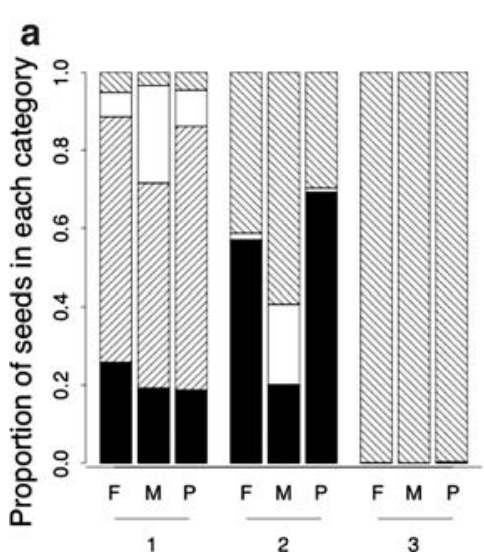

Fig. 1 The fraction of lost, germinated, viable and dead seeds for (a) Veratrum album and (b) Gentiana lutea in forests (F), meadows (M) and pastures (P) in the first-, second- and third-year of exhumation. The proportion of seeds in each category was calculated from the total number of seeds initially put in the replicate seed bags per

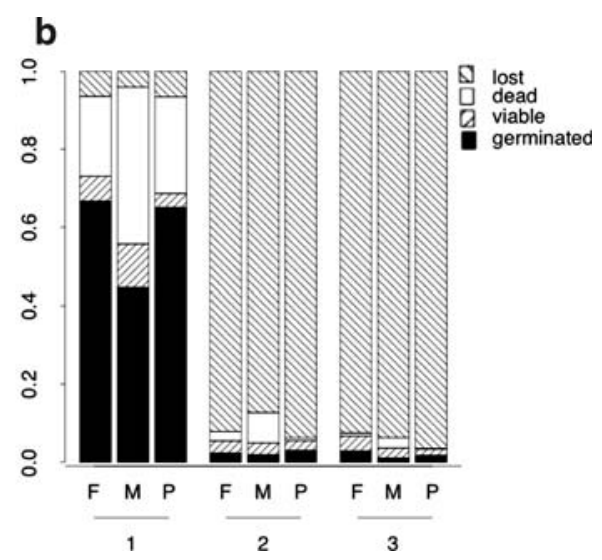

species per habitat. Seeds loss equals the difference between the 50 seeds in each bag and the number of seeds retrieved at each exhumation. See Table 3 for significance of treatment effects calculated using linear mixed-effects models 
and $8.6 \pm 1.0 \%$ of the $G$. lutea seeds could be retrieved in the second-year of exhumation (Fig. 1). Relatively few of the $V$. album and $G$. lutea seeds survived until reaching their thirdyear (V. album: $0.15 \%$; G. lutea: $5.72 \%$ ).

Seed germination in the first- and second-year of exhumation

The majority of the retrieved $V$. album seeds delayed germination until reaching their second-year whilst the fraction of $G$. lutea seeds germinating decreased as seeds aged (Fig. 1, Table 3). Although germination tended to be lower in hay meadows (Fig. 1), this effect was not significant (Table 3). However, habitat-specific differences in seed germination became more pronounced with increasing age of the retrieved seeds (Fig. 1, Table 3).

Seed viability in the first- and second-year of exhumation

The majority of $V$. album seeds were viable but did not germinate in their first-year and lost dormancy during their second-year (Fig. 1a). In contrast, G. lutea seeds showed the opposite response (Fig. 1b); i.e., the proportion of the retrieved seeds being viable increased with increasing seed age (Table 3 ). Seed viability was not affected by habitat (Table 3).

Seed mortality in the first- and second-year of exhumation

Overall, the mortality fraction of the retrieved $G$. lutea seeds was significantly higher compared to $V$. album seeds ( $G$. lutea: $0.303 \pm 0.006$;
V. album: $0.146 \pm 0.007$, Table 3). After correcting for initial differences in seed viability, the mortality fraction of G. lutea seeds was still significantly higher compared to V. album seeds, suggesting that the observed difference was the result of differential mortality rates. Although seed age and habitat did not have a significant effect on seed mortality independently (Fig. 1, Table 3), seed mortality did differ significantly between habitats depending on the age of the retrieved seeds (Fig. 1, Table 3).

The fate of seeds in the third-year of exhumation

As little as $0.15 \%$ of all sown $V$. album seeds survived until reaching their third-year probably due to the extremely high proportion of seeds germinating in their second-year (Fig. 1a). In spring 2005, the $G$. lutea soil seed bank was reduced to approximately $5 \%$ of its original size. Consistent with germination fractions of $G$. lutea in the first 2 years of exhumation, seed germination was considerably lower in hay meadows compared to forests and pastures in the third-year of exhumation (Fig. 1b, forest: $0.267 \pm 0.104$; hay meadow: $0.119 \pm 0.047$; pasture: $0.336 \pm 0.143$ ). A similar picture emerges from the seed mortality fractions, with mortality of the retrieved G. lutea seeds being over 10-fold higher in hay meadows compared to pastures and forests (forest: $0.075 \pm 0.036$; hay meadow: $0.532 \pm 0.176$; pasture: $0.033 \pm 0.030$ ) . In the third-year of exhumation, dormancy of $G$. lutea seeds differed considerably between habitats, being highest in forests (forest: $0.675 \pm 0.129$; hay meadow: $0.350 \pm 0.157$; pasture: $0.233 \pm 0.131$ ) .

Table 3 The results of the linear mixed-effects model for the seed germination, viability and mortality fractions in the first 2 years of the experiment, with seed age, habitat (nested in site) and species as fixed explanatory variables

\begin{tabular}{llll}
\hline & Germination & Viability & Mortality \\
\hline Seed age & $\mathrm{F}_{1,45}=844.62^{* *}$ & $\mathrm{~F}_{1,47}=51.98^{* *}$ & $\mathrm{~F}_{1,46}=0.17^{\mathrm{NS}}$ \\
Habitat & $\mathrm{F}_{2,10}=0.77^{\mathrm{NS}}$ & $\mathrm{F}_{2,10}=1.65^{\mathrm{NS}}$ & $\mathrm{F}_{2,10}=2.74^{\mathrm{NS}}$ \\
Species & $\mathrm{F}_{1,45}=6996.77^{* *}$ & $\mathrm{~F}_{1,47}=389.55^{* *}$ & $\mathrm{~F}_{1,46}=70.81^{* *}$ \\
Seed age $\times$ Habitat & $\mathrm{F}_{2,45}=13.47^{* *}$ & $\mathrm{~F}_{1,47}=454.61^{* *}$ & $\mathrm{~F}_{2,46}=5.56^{* *}$ \\
Seed age $\times$ Species & $\mathrm{F}_{1,45}=7917.36^{* *}$ & \\
\hline
\end{tabular}

Notes. Blank spaces in the LME table indicate that these terms were dropped from the model after comparison of the maximum likelihood ratios of the full and depleted models. The most parsimonious model was refitted using restricted maximum likelihood

NS $P>0.05 ; * * P<0.001$ 


\section{Discussion}

The majority of freshly collected $V$. album and $G$. lutea seeds were viable but did not germinate. This is consistent with other alpine plant species, which delayed seed germination until reaching at least the next growing season (e.g., Meyer et al. 1995; Cavieres and Arroyo 2001; Shimono and Kudo 2005). This innate dormancy prevents precocious germination beneath the snow pack, finetuning the timing of seed germination to favour seedling establishment.

Our study shows that the long-lived clonal weeds $V$. album and $G$. lutea were able to delay seed germination, enabling them to form a shortterm persistent soil seed bank (Thompson et al. 1997). In the third-year, the experimental soil seed banks of both species were nearly depleted, having declined to less than $5 \%$ of their original size. Consistent with our results, theoretical models predict that the ability to reproduce by vegetative growth in addition to reproduction by seeds will select for reduced seed dormancy and consequently a rapid decline in the soil seed bank (e.g., Venable and Brown 1988; Rees 1994, 1996; Forbis 2003). Alternatively, Meyer and Pendleton (2005) suggested that the presence of only a transient or short-term persistent seed bank could represent a response to long-term selection for germination immediately following a mast year, when predation risk to individual seeds is expected to be reduced.

A recent study by Van Mourik et al. (2005) demonstrated that estimates of seed bank depletion rates using the seed bag burial method might be too high, due to elevated levels of pathogens at high seed densities which might influence seed mortality. Although it is unlikely that the seed density used in the present experiment had a negative effect on seed survival due to elevated levels of soil- or seed-borne pathogenic fungi, the cause of seed bank depletion is not completely clear from this study. Potential causes of depletion and the low retrieval of seeds are (1) germination followed by decomposition; (2) physical removal of seeds from bags by soil-borne invertebrates; and (3) attack by pathogenic fungi (e.g., Crist and Friese 1993; Lonsdale 1993; Dalling et al. 1998). These causes could be investigated by experiments in which invertebrates, fungi or both are excluded by using different mesh sizes, fungicides and sterilization treatments. The direct loss of seeds through the nylon mesh of the bags could have been another possible cause of poor recovery. However, in the first-year of exhumation, we did not find any differences in recovery between the relatively large $V$. album and small G. lutea seeds, indicating this is not a likely cause of the observed seed bank depletion.

Interestingly, $V$. album and G. lutea had strikingly different germination strategies. The majority of the retrieved $V$. album seeds delayed germination until reaching their second-year, probably due to a requirement of after-ripening of seeds in the soil. Conversely, G. lutea seeds predominantly germinated in the first-year of retrieval and dormancy fractions of $G$. lutea seeds increased over time; G. lutea seeds that did not have the opportunity to germinate in their first-year were probably still viable in their second-year, whilst those that germinated or were dead might have been more prone to decay in the soil (Murdoch and Ellis 1992), leading to a relative increase of seed dormancy over time. Along with seed shape and vertical distribution of seeds in the soil, seed size is often ascribed to explain differences in seed longevity among species (e.g., Bekker et al. 1998a). Species with large individual seeds are predicted to have reduced dormancy because their seedlings can draw on a larger food reserve and establish in relatively unfavourable environments (Rees 1996); consistently, longevity and dormancy of the retrieved G. lutea seeds was higher compared to the relatively large $V$. album seeds.

Most organisms have evolved life history traits, such as seed dormancy, that facilitate survival and reproduction in habitats with unpredictable conditions (Cáceres and Tessier 2003; Pfister and Stevens 2003). The importance of delaying germination may vary for populations in different habitats, highlighting the importance of life history adaptations that may evolve under specific selective forces in the different parts of a species' range (Volis et al. 2004). Our study did not compare the behaviour of seeds collected from different habitats, but rather focused on plasticity of seed germination and dormancy responses in environmentally contrasting habitats. Although, 
several studies have shown that germination differences have a strong genetic basis both among populations and among plants in a population (e.g., Philippi 1993), population-based differences in seed germination do not always appear to have a genetic basis (e.g., Panetta and Randall 1993). Germination timing is known to be highly plastic in response to environmental conditions experienced both during seed maturation and after dispersal (reviewed in Baskin and Baskin 1998; Donohue et al. 2005a, b). Plasticity of germination responses under different environmental conditions may be of importance as seeds that germinate in different conditions may experience different selective regimes for post-germination traits (Evans and Cabin 1995). Adaptive dormancy mechanisms and requirements for germination of alpine plants have previously been shown to be habitat specific (e.g., altitude; Allen and Meyer 1998). Although we did not find any clear-cut difference in seed behaviour among habitats, there was a tendency for reduced germination and increased mortality in hay meadows. Nevertheless, habitat-specific differences in seed germination increased as seeds aged, with germination fractions being lowest in more humid hay meadows. This suggests that the negative effects of anoxic conditions became more pronounced with increasing seed age, emphasizing the importance of measuring seed behaviour over multiple years and environmental conditions. A similar picture emerged from the mortality data: differences in seed mortality between habitats increased as seeds aged. In agreement with our results, Murdoch and Ellis (1992) found a rapid decline in seed longevity of lettuce seeds with increasing soil moisture under anoxic conditions.

In conclusion, whilst both $V$. album and $G$. lutea were able to delay seed germination, only a very small percentage of the seeds initially put into the ground was still viable after 3 years ( $<5 \%$ of the total seed lot). Having limited seed dormancy, the clonal weeds V. album and G. lutea thus lack the ability to form a long-term persistent seed bank. Hence, seed bank depletion appears to be important for the population dynamics of these species. This has important implications for the population management of these weeds as future reinvasion of sites from the soil seed bank is unlikely after populations have been eradicated (e.g., by manual removal of shoots or limited application of herbicides). Interestingly, although $V$. album and $G$. lutea appear to have similar life histories we found differential seed germination strategies, which in theory could mitigate interspecific competition and alter the outcome of weed population management strategies. Estimates of seed bank depletion rates over multiple years are essential for modelling and management of unpalatable perennial plant populations. Therefore, knowledge of the differential behaviour of individual species over multiple years and varying environmental conditions is necessary for effective control of diverse weed populations and for anticipating the effects of management practices on weed population dynamics. Surprisingly, the majority of studies investigating soil seed bank dynamics consider either just seed behaviour in the following year, only a single plant species and/or a limited number of replicated habitats from the species distribution range.

Acknowledgements We thank Tom van Mourik, Tadeusz Kawecki and two anonymous reviewers for helpful comments on the manuscript, Michiel Vos, Christian Smit and Urs Treier for practical assistance and Renée Bekker for valuable technical advice. The project was funded by the research programme NRP-48 on "Landscapes and habitats of the Alps" of the Swiss National Science Foundation to HMS.

\section{References}

Adondakis S, Venable DL (2004) Dormancy and germination in a guild of Sonoran Desert annuals. Ecology 85:2582-2590

Allen SP, Meyer SE (1998) Ecological aspects of seed dormancy loss. Seed Sci Res 8:183-191

Ammon HU, Muller-Scharer H (1999) Prospects for combining biological weed control with integrated crop production systems, and with sensitive management of alpine pastures in Switzerland. Zeitschrift fur Pflanzenkrankheiten und Pflanzenschutz-Journal of Plant Diseases and Protection 106:213-220

Arroyo MTK, Cavieres LA, Castor C, Humana AM (1999) Persistent soil seed bank and standing vegetation at a high alpine site in the central Chilean Andes. Oecologia 119:126-132

Augustine DJ, McNaughton SJ (1998) Ungulate effects on the functional species composition of plant communities: herbivore selectivity and plant tolerance. J Wildl Manage 62:1165-1183 
Baskin CC, Baskin JM (1998) Seeds: ecology, biogeography and evolution of dormancy and germination. Academic Press, San Diego, CA

Bekker RM, Bakker JP, Grandin U, Kalamees R, Milberg P, Poschlod P, Thompson K, Willems JH (1998a) Seed size, shape and vertical distribution in the soil: indicators of seed longevity. Func Ecol 12:834-842

Bekker RM, Knevel IC, Tallowin JBR, Troost EML, Bakker JP (1998b) Soil nutrient effects on seed longevity: a burial experiment with fen-meadow species. Func Ecol 12:673-682

Bekker RM, Oomes MJM, Bakker JP (1998c) The impact of groundwater level on soil seed bank survival. Seed Sci Res 8:399-404

Bierzychudek P (1985) Patterns in plant parthenogenesis. Experientia 41:1255-1264

Buckley YM, Rees M, Paynter Q, Lonsdale M (2004) Modelling integrated weed management of an invasive shrub in tropical Australia. J Appl Ecol 41:547-560

Buhler DD, Hartzler RG (2001) Emergence and persistence of seed of velvetleaf, common waterhemp, woolly cupgrass, and giant foxtail. Weed Sci 49:230-235

Cáceres CE, Tessier AJ (2003) How long to rest: the ecology of optimal dormancy and environmental constraint. Ecology 84:1189-1198

Cavieres LA, Arroyo MTK (2001) Persistent soil seed banks in Phacelia secunda (Hydrophyllaceae): experimental detection of variation along an altitudinal

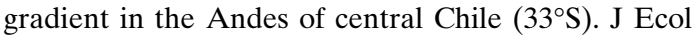
89:31-39

Cottrell HJ (1947) Tetrazolium salt as a seed germination indicator. Nature 159:748

Crist TO, Friese CF (1993) The impact of fungi on soil seeds: implications for plant and granivores in a semiarid shrub-steppe. Ecology 74:2231-2239

Dalling JW, Swaine MD, Garwood NC (1998) Dispersal patterns and seed bank dynamics of pioneer trees in moist tropical forest. Ecology 79:564-578

Donohue K, Dorn L, Griffith C, Kim E, Aguilera A, Polisetty CR, Schmitt J (2005a) The evolutionary ecology of seed germination of Arabidopsis thaliana: variable natural selection on germination timing. Evolution 59:758-770

Donohue K, Dorn L, Griffith C, Kim E, Aguilera A, Polisetty CR, Schmitt J (2005b) Environmental and genetic influences on the germination of Arabidopsis thaliana in the field. Evolution 59:740-757

Easterling MR, Ellner SP (2000) Dormancy strategies in a random environment: comparing structured and unstructured models. Evol Ecol Res 2:387-407

Ellner S (1985) ESS germination strategies in randomly varying environments 1 . Logistic-type models. Theor Popul Biol 28:50-79

Evans AS, Cabin RJ (1995) Can dormancy affect the evolution of post-germination traits-the case of Lesquerella fendleri. Ecology 76:344-356

Forbis TA (2003) Seedling demography in an alpine ecosystem. Am J Bot 90:1197-1206
Funes G, Basconcelo S, Diaz S, Cabino M (2003) Seed bank dynamics in tall-tussock grasslands along an altitudinal gradient. J Veg Sci 14:253-258

Galatowitsch SM, van der Valk AG (1996) The vegetation of restored and natural prairie wetlands. Ecol Appl 6:102-112

Kery M, Matthies D, Spillmann HH (2000) Reduced fecundity and offspring performance in small populations of the declining grassland plants Primula veris and Gentiana lutea. J Ecol 88:17-30

Kleijn D, Müller-Schärer H (2006) The relation between unpalatable species, nutrients and plant species richness in Swiss montane pastures. Biodivers Conserv (in press). DOI 10.1007/s1053100530125

Kleijn D, Steinger T (2002) Contrasting effects of grazing and hay cutting on the spatial and genetic population structure of Veratrum album, an unpalatable, longlived, clonal plant species. J Ecol 90:360-370

Kleijn D, Treier UA, Müller-Schärer H (2005) The importance of nitrogen and carbohydrate storage for plant growth of the alpine herb Veratrum album. New Phytol 166:565-575

Klinkhamer PGL, de Jong TJ, Metz AJ, Val J (1987) Life history tactics of annual organisms: the joint effect of dispersal and delayed germination. Theor Popul Biol 32:127-156

Körner C (1999) Alpine plant life: functional plant ecology of high mountain ecosystems. Springer, Berlin

Lonsdale WM (1993) Losses from the seed bank of $M i$ mosa pigra: soil micro-organisms vs. temperature fluctuations. J Appl Ecol 30:654-660

MacDonald D, Crabtree JR, Wiesinger G, Dax T, Stamou N, Fleury P, Lazpita JG, Gibon A (2000) Agricultural abandonment in mountain areas of Europe: environmental consequences and policy response. J Environ Manage 59:47-69

Menges ES (2000) Population viability analyses in plants: challenges and opportunities. Trends Ecol Evol 15:51-56

Meyer SE, Kitchen SG, Carlson SL (1995) Seed-germination timing patterns in intermountain Penstemon (Scrophulariaceae). Am J Bot 82:377-389

Meyer SE, Pendleton BK (2005) Factors affecting seed germination and seedling establishment of a longlived desert shrub (Coleogyne ramosissima: Rosaceae). Plant Ecol 178:171-187

Murdoch AJ, Ellis RH (1992) Longevity, viability and dormancy. In: Fenner M (ed) Seeds. The ecology of regeneration in plant communities. CABI, Wallingford

Panetta FD, Randall RP (1993) Variation between Emex australis populations in seed dormancy non-dormancy cycles. Aust J Ecol 18:275-280

Pfister CA, Stevens FR (2003) Individual variation and environmental stochasticity: implications for matrix model predictions. Ecology 84:496-510

Philippi T (1993) Bet-hedging germination of desert annuals: beyond the first year. Am Nat 142:474-487

Pinheiro JC, Bates DM (2000) Mixed-effects models in S and S-plus. Springer, New York 
Rees M (1994) Delayed germination of seeds - a look at the effects of adult longevity, the timing of reproduction, and population age/stage structure. Am Nat 144:43-64

Rees M (1996) Evolutionary ecology of seed dormancy and seed size. Philos T Roy Soc B 51:1299-1308

Rice KJ, Dyer AR (2001) Seed aging, delayed germination and reduced competitive ability in Bromus tectorum. Plant Ecol 155:237-243

Sawma JT, Mohler CL (2002) Evaluating seed viability by an unimbibed seed crush test in comparison with the tetrazolium test. Weed Technol 16:781-786

Schaffner U, Kleijn D, Brown V, Müller-Schärer H (2001) Veratrum album L. in montane grasslands: a model system for implementing biological control in land management practices of high biodiversity habitats. Biocontrol 22:19N-28N

Schlapfer M, Zoller H, Korner C (1998) Influences of mowing and grazing on plant species composition in calcareous grassland. Bot Helv 108:57-67

Shimono Y, Kudo G (2005) Comparisons of germination traits of alpine plants between fellfield and snowbed habitats. Ecol Res 20:189-197

Ter Heerdt GNJ, Verweij GL, Bekker RM, Bakker JP (1996) An improved method for seed bank analysis: seedling emergence after removing the soil by sieving. Funct Ecol 10:144-151
Thompson K, Grime JP (1979) Seasonal variation in the seed bank of herbaceous species in ten contrasting habitats. J Ecol 67:893-921

Thompson K, Bakker JP, Bekker RM (1997) Soil seed banks of North West Europe: methodology, density and longevity. Cambridge University Press, Cambridge

Vandenberghe C, Freléchoux F, Moravie M, Gadallah F, Buttler A (2006) Short-term effects of cattle browsing on tree sapling growth in mountain wooded pastures. Plant Ecol (in press). DOI 10.1007/s1125800691601

Van Mourik TA, Stomph TJ, Murdoch AJ (2005) Why high seed densities within buried mesh bags may overestimate depletion rates of soil seed banks. J Appl Ecol 42:299-305

Venable DL, Brown JS (1988) The selective interaction of dispersal, dormancy, and seed size as adaptations for reducing risk in variable environments. Am Nat 131:360-384

Volis S, Mendlinger S, Ward D (2004) Demography and role of the seed bank in Mediterranean and desert populations of wild barley. Basic Appl Ecol 5:53-64 